\title{
Effect of Crop Rotations on Rotylenchulus reniformis Population Structure
}

Megan Leach and Paula Agudelo, Department of Entomology, Soils, and Plant Sciences, 206 Long Hall, Clemson University, Clemson, SC 29634; and Amy Lawton-Rauh, Department of Genetics and Biochemistry, 100 Jordan Hall, Clemson University, Clemson, SC 29634

\begin{abstract}
Rotylenchulus reniformis is a highly variable nematode species and an economically important pest in many cotton fields across the southeastern United States. Rotation with resistant or poor host crops is a method for management of reniform nematode. We studied the effect of six planting schemes covering four 120-day planting cycles on the predominant genotype of $R$. reniformis. Rotations used were: (i) cotton to corn; (ii) susceptible soybean to corn; (iii) resistant soybean to cotton; (iv) corn to cotton; (v) continuous susceptible soybean; (vi) continuous cotton. After each 120-day cycle, amplified fragment length polymorphisms (AFLPs) produced from four primer pairs were used to
\end{abstract}

Abstract

Leach, M., Agudelo, P., and Lawton-Rauh, A. 2012. Effect of crop rotations on Rotylenchulus reniformis population structure. Plant Dis. 96:24-29.

determine the effect of crop rotation on the predominant genotype of reniform nematode. A total of 279 polymorphic bands were scored using four primer combinations. Distinct changes in genotype composition were observed following rotations with resistant soybean or corn. Rotations involving soybean (susceptible and resistant) had the greatest effect on population structure. The characterization of field population variability of reniform nematode and of population responses to host plants used in rotations can help extend the durability of resistant varieties and can help identify effective rotation schemes.
Rotylenchulus reniformis (reniform nematode) can parasitize over 300 plant species including soybean and cotton (22). In the United States, reniform nematode is considered a major nematode pest of Upland cotton (Gossypium hirsutum), causing an estimated loss of 203,720 bales in 2009 when it was the primary nematode pest of Upland cotton in Alabama, Louisiana, Mississippi, and Tennessee (1). In the same year, reniform nematode caused greater estimated losses than root-knot nematodes for cotton producers in these states.

The use of nematicides for reniform nematode population density reduction can be financially and environmentally costly. Alternatives to nematicides include soil amendments, host plant resistance, cover cropping, and crop rotations (6). Increasing host plant resistance is a preferred method of managing plant-parasitic nematodes, but resistance to the reniform nematode has not been identified in Upland cotton $(21,28)$. Resistance has been introgressed from Gossypium longicalyx (20) in breeding lines, but there is currently no commercially available cotton cultivar with resistance to reniform nematode.

Crop rotation with corn (Zea mays), a poor host for reniform nematode (4), or a resistant soybean (Glycine max) cultivar is a prescribed method of control for cotton producers in Georgia, North Carolina, and Tennessee $(2,13,17)$. Several studies have looked at the effect of crop rotation on reniform nematode reproduction. Certain rotations suppressed reniform nematode population densities compared to continuous cotton $(3,7,8,19,20,24)$. Cotton yields have also been higher following corn or resistant soybean versus plots planted with continuous cotton in North Carolina, Georgia, Arkansas, and Alabama $(3,7,8,19,20,24)$. Both corn and resistant soybean can decrease reniform nematode population density in the year they are grown, but sharp increases in numbers have been reported when cotton is returned as a host $(7,8,18)$. Researchers have found no significant differences among cotton cultivars or corn hybrids used in rotations, suggesting it is a species effect and not dependent on cultivar (24).

Corresponding author: Paula Agudelo, E-mail: pagudel@clemson.edu

Accepted for publication 2 August 2011.

http://dx.doi.org/10.1094/PDIS-02-11-0131

(C) 2012 The American Phytopathological Society
Despite the potential for adaptation, differentiation, and spread of a resistance-breaking allele among expanding populations of reniform nematodes, the effect of crop rotations on reniform nematode population structure has not been studied. Use of resistant cultivars or poor hosts may provide a method of nematode control that imposes a selective pressure on nematodes, allowing a population to overcome host plant resistance (16,27). Amplified fragment length polymorphisms (AFLPs) offer a method for genotyping that allows for analysis of an entire genome without prior sequence information (29) and are a useful tool for revealing genetic diversity within a species. AFLPs may also allow for the analysis of population structure changes induced by a host plant. Our objective was to determine the effect of crop rotations on the population structure of reniform nematode using AFLP markers as a step toward understanding the interactions between genetic connectivity and the mediation of reniform nematode population expansion.

\section{Materials and Methods}

Crop rotations. The experiments were conducted in a greenhouse to determine if there was an effect of host on reniform nematode genotype that may need to be evaluated in a field or microplot. Field soil infested with $R$. reniformis was obtained from a cotton field located near St. Matthews, SC. An aliquot of 1,000 individuals extracted from the infested field soil served as the baseline for all genotype comparisons. The field soil was mixed with pasteurized loamy sand in a 38-liter plastic container $(61.25 \times$ $41.15 \times 22.43 \mathrm{~cm}$ ), and approximately 3,000 vermiform $R$. reniformis per $200 \mathrm{~cm}^{3}$ were added. For each rotation, four seeds were planted per container. A total of six rotation schemes were studied. Rotations included: (i) cotton, corn, cotton, corn; (ii) susceptible soybean, corn, susceptible soybean, corn; (iii) resistant soybean, cotton, resistant soybean, cotton; (iv) corn, cotton, corn, cotton; (v) continuous susceptible soybean; (vi) continuous cotton. Cotton cultivar 'Deltapine 50' (PI 529566), corn hybrid Funk's Waxy (PI 504055), and soybean cultivars 'Braxton' (susceptible) (PI 548659) and 'Forrest' (resistant) (PI548655) were used. After each 120-day cycle, the plants were destroyed, and four soil samples of $\sim 200 \mathrm{~cm}^{3}$ were collected from each rotation sequence, and vermiform reniform nematodes were counted. The soil that was removed for nematode counts was replaced with a pasteurized loamy sand. The next cycle was planted directly into the designated rotation container, for a total of four cycles. 
DNA extraction. Following each rotation cycle, all four nematode samples were combined to remove any effect of specific plant genotype that is not indicative of the species or cultivar as a whole, and four aliquots of 1,000 vermiform reniform nematodes were transferred into $1.5-\mathrm{ml}$ tubes per rotation scheme. DNA was extracted from nematode aliquots using E.Z.N.A. Mag-Bind Blood DNA Kit (Omega Bio-Tek) with a slight modification to the manufacturer's protocol. Prior to adding Elution Buffer in step 1, nematodes were frozen in liquid nitrogen and then crushed with a pestle. The remaining steps followed the manufacturer's protocol, except for step 20. Instead of adding 100 to $200 \mu \mathrm{l}$ of Elution Buffer, only $50 \mu \mathrm{l}$ was added to increase DNA concentration. DNA was stored at $-20^{\circ} \mathrm{C}$.

AFLP amplification. AFLP analysis was performed using AFLP Analysis System I (Invitrogen). To begin, $10 \mu \mathrm{l}$ of DNA extract was used for restriction digestion with EcoRI and MseI enzymes, and the manufacturer's protocol was followed. A slight modification was implemented during preamplification reactions. Instead of 20 cycles for preamplification polymerase chain reaction (PCR), 25 cycles were performed. Preamplification PCR reactions were performed in a PCR Sprint thermocycler. After preamplification PCR, a 1:20 dilution of PCR product was used instead of a 1:50 dilution to increase product concentration for selective amplification. Selective amplification was performed using four primer pairs each with a fluorescently labeled forward primer.
Selective nucleotides on primer pairs were as follows: (i) E-AAG, M-CTA; (ii) E-ACA, M-CAA; (iii) E-ACA, M-CAC; (iv) E-ACG, MCTC. Fragments were sequenced using an ABI3730xl DNA Analyzer and visualized using GeneMapper V 4.0. GeneMapper was used to construct a genotype for samples consisting of a binary system of 0 for allele absence and 1 for allele presence.

Data analysis. Genotypes produced from GeneMapper were analyzed for the best fit number of population groupings using the genotype assignment program STRUCTURE V 2.3 (10). Genotypes from four primer pairs were combined per sample to give a higher resolution image of predominant genotype following rotation cycles. An initial burn-in period of 200,000 iterations was used followed by 500,000 MCMC iterations for all runs of STRUCTURE. Models were altered to determine the model of best fit for analysis of each rotation scheme. An admixture model with allele frequencies correlated was used for independent analysis of each rotation scheme. The admixture model allows the program to look at each genotype as having ancestry from multiple clusters, and each individual may not belong to a single cluster. Correlated allele frequency models allows for analysis when genotypes may be quite similar and can improve clustering for closely related populations. The value of population cluster, K, was varied from 1 to 6 for each rotation scheme and run several times to confirm that results across multiple runs of STRUCTURE were similar. In STRUCTURE, K represents the number of populations characterized by a set of
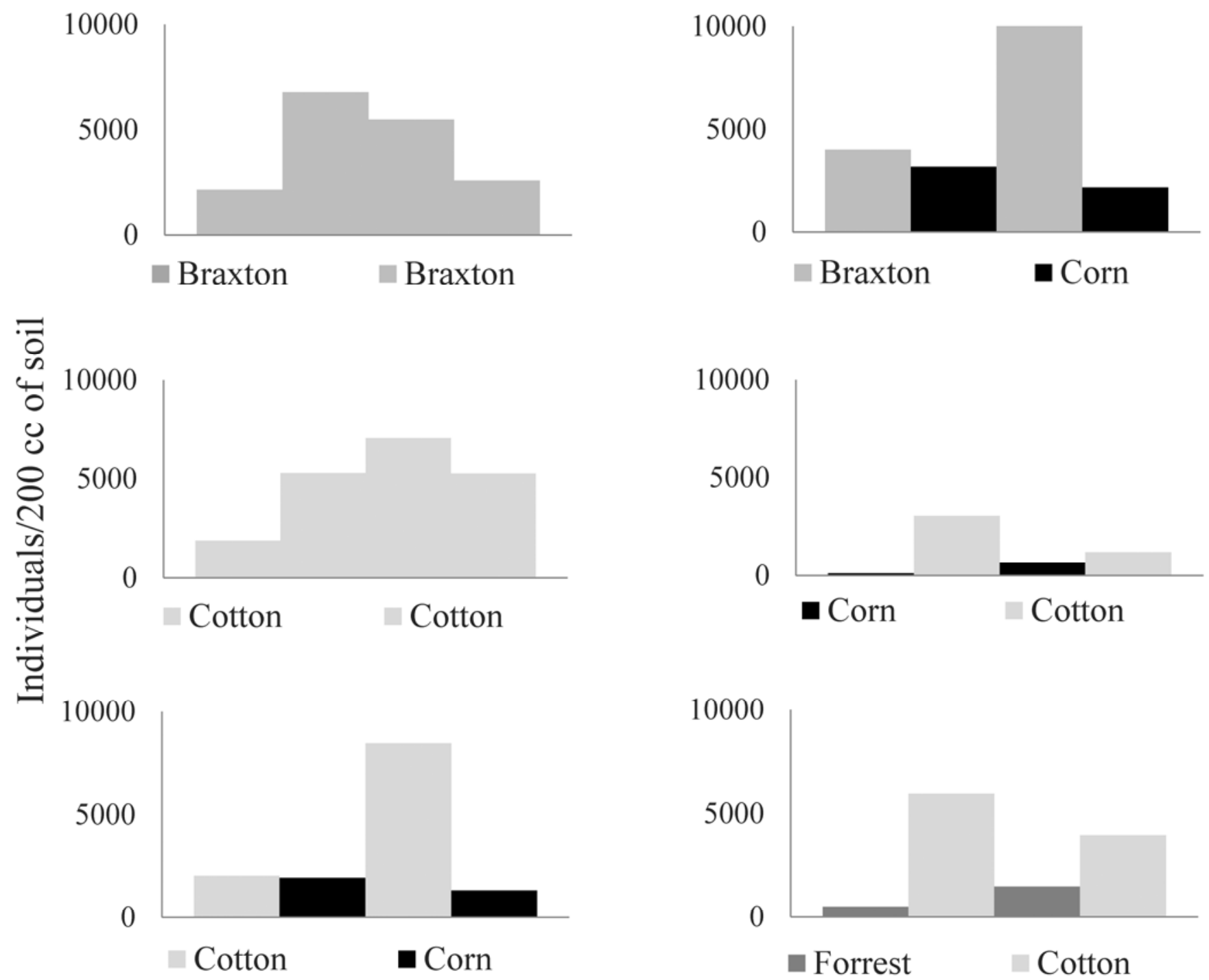

Fig. 1. Mean reniform nematode counts from soil samples following four 120-day crop cycles for six rotation schemes. Rotation schemes included: Braxton (susceptible soybean cultivar)-Braxton-Braxton-Braxton, Cotton-Cotton-Cotton, Braxton-Corn-Braxton-Corn, Corn-Cotton-Corn-Cotton, Cotton-Corn-Cotton-Corn, and Forrest (resistant soybean cultivar)-Cotton-Forrest-Cotton. 
allele frequencies at all loci. Individuals are assigned to groupings in which allele frequencies are similar. The program DISTRUCT (23) was used for graphic representation of genotype similarity for each cycle.

\section{Results}

The population densities observed after each rotation cycle behaved as expected based on the known host suitability of the crops and cultivars (Fig. 1). Reniform nematode population densities in soil were lowest where resistant soybean cultivar Forrest (ranged from 495 to $1,470 / 200 \mathrm{~cm}^{3}$ ) or corn (ranged from 116 to 3,175/200 $\mathrm{cm}^{3}$ ) were included in the crop sequence. Population densities were highest after continuous cotton (ranged from 1,879 to 9,440/200 $\mathrm{cm}^{3}$ ) or susceptible soybean cultivar Braxton (ranged from 2,153 to $10,378 / 200 \mathrm{~cm}^{3}$ ).

AFLP analysis found 279 polymorphic bands from the four primer combinations that had six selective nucleotides in each primer pair. A log-likelihood ratio test was used to determine the best fit model based on log probability values assigned by STRUCTURE analysis. The best fit model was determined to be an admixture model with allele frequencies correlated. STRUCTURE was also used to determine the best fit number of clusters, or population groupings, from the value of $\mathrm{K}$ (Table 1) with the highest log probability $(\ln P(D))$. Population groupings were determined for each cycle.

The rotation scheme of continuous susceptible soybean Braxton (BBBB) resulted in the best fit number of population groupings being $2(\mathrm{~K}=2, \ln \mathrm{P}(\mathrm{D})=-1,546.6)$. With this cropping sequence, genotypes were similar to the original field genotype after four 120-day cycles (Fig. 2A). On continuous Braxton, the original field genotype was maintained through the four rotation cycles even though it was not always the dominant genotype (e.g., cycle 2). No distinct effect on genotype was observed from host selection pressure when continuous Braxton was used as a host.

The rotation scheme consisting of continuous cotton (DDDD) maintained a high level of diversity throughout the experiment and resulted in the best fit number of population groupings being 3 ( $\mathrm{K}$ $=3, \ln \mathrm{P}(\mathrm{D})=-1623.8)$. Portions similar to the original field genotype were maintained throughout the 4 cycles as was also observed from the other continuous susceptible host rotation scheme BBBB (Fig. 2E). However, more genotype diversity was observed when cotton was grown continuously than with susceptible soybean. Rotation sequence DDDD did not have a distinct genotype between all four replicates following each cycle. Portions of each genotype following all cycles were similar to previous and post cycle genotypes as well as similar to the original field genotype. Continuous cotton did not appear to exert host selection pressure on reniform nematode after four 120-day cycles but allowed for more diversity in genotype than continuous susceptible soybean.

The rotation scheme alternating susceptible soybean Braxton with corn (BCBC) had a best fit number of population groupings of $5(\mathrm{~K}=5, \ln \mathrm{P}(\mathrm{D})=-1,520.1)$. After the first sequence of Braxton and corn, genotypes from three replicates were still similar to the original field genotype (Fig. 2B). When corn was included (cycle

Table 1. Six rotation schemes used to determine host selection pressure on Rotylenchulus reniformis, rotation abbreviation, number of distinct population groupings $(\mathrm{K})$ inferred using genotype assignment tests implemented in STRUCTURE V 2.3 and $\log$ probability $(\ln P(D))$ of results from STRUCTURE V 2.3 analysis

\begin{tabular}{lccc}
\hline Rotation scheme & Abbreviation & K & LnP(D) \\
\hline Braxton-Braxton & BBBB & 2 & $-1,546.6$ \\
Braxton-Corn & BCBC & 5 & $-1,520.1$ \\
Corn-Cotton & CDCD & 3 & $-1,480.0$ \\
Cotton-Corn & DCDC & 5 & $-1,248.6$ \\
Cotton-Cotton & DDDD & 3 & $-1,623.8$ \\
Forrest -Cotton $^{\text {a }}$ & FDFD & 4 & -980.2 \\
\hline
\end{tabular}

${ }^{a}$ Braxton is a susceptible soybean cultivar for $R$. reniformis.

${ }^{\mathrm{b}}$ Forrest is a resistant soybean cultivar for $R$. reniformis.
2 ), a portion of the genotype similar to the original field genotype was still detectable in all four replicates $(\sim 5.5 \%)$. When Braxton was again returned as the host, $100 \%$ of the genotypes from all four replicates grouped similarly and were different from any other genotypes found in the BCBC rotation. This result was again observed when corn was returned in cycle 4 . Cycles 2 through 4 each resulted in a distinctly unique grouping of genotypes that was not observed after cycle 1. Although Braxton is susceptible, similarity to the field genotype and cycle 1 genotype were not detectable in cycle 3 when Braxton was returned as the host. In this cropping sequence, once corn was introduced in the rotation, distinct population structuring began to occur in the remaining cycles.

The rotation scheme alternating the resistant soybean Forrest with cotton (FDFD) had a best fit number of population groupings of $4(\mathrm{~K}=4, \ln \mathrm{P}(\mathrm{D})=-980.2)$. No genotypes were determined following cycle 1 due to low recovery of vermiform reniform nematodes. Only two replicates were recovered after cycle 3, but four replicates were recovered when cotton was the host (cycles 2 and 4). Following each crop, the nematodes that were recovered had nearly $100 \%$ homogeneity in genotypes following each rotation cycle (Fig. 2E). No cycles grouped similarly. Similarity to the original field genotype after cycle 1 could not be determined. Genotypes from cycle 2 and 3 had less than $0.5 \%$ homogeneity with original field genotype, and no similarity to the original field genotype was observed in cycle 4 . In cycles 2 and 4, when cotton was the host, genotypes exhibited $0 \%$ homogeneity between genotypes from the two cycles. The predominant genotype following cotton as a host in cycle 2 was not maintained and was not similar to genotypes after cotton was returned as a host in cycle 4 following resistant soybean as the host.

The rotation scheme alternating cotton with corn (DCDC) had a best fit number of population groupings of $5(\mathrm{~K}=5, \ln \mathrm{P}(\mathrm{D})=$ $-1248.6)$. The original field genotype was not similar to genotypes following corn in cycles 2 and 4 but was similar when cotton was the host in cycle 1 and when reniform nematode numbers were increased in cycle 3 (Fig. 2D). When corn was included in the rotation, there was $100 \%$ homogeneity between replicate genotypes. Only two replicates were recovered following cycle 4. Reniform nematode genotypes recovered following cycle 4 were similar to a portion of the genotype from cycle $3(25.9,29.9,38.0$, and $7.9 \%$ homogeneity). The predominant genotype following cycle 1 was different than the genotypes in the subsequent three cycles after corn was included. The predominant genotype following cycle 3 was not homogeneous with any other cycle's predominant genotype, but diversity was still maintained when cotton was the host.

A different result was observed when corn was grown first in the sequence followed by cotton (CDCD). The best fit number of population groupings was $3(K=3, \ln P(D)=-1,480.0)$. Only one replicate was able to be recovered following corn in both cycles 1 and 3 . There was $100 \%$ homogeneity of genotypes following cycles 1 and 3 with the original field genotype (Fig. 2C). A portion of the field genotype was similar to genotypes after cycle 4 (cotton) in two of the four replicates. This suggests that there was an effect of rotation sequence on predominant genotypes. The similarity between cycles 1 and 3 with the field genotype suggests that the majority of individuals recovered were individuals that remained viable in the soil until a suitable host was returned.

When cotton was grown in rotation with the resistant soybean Forrest, replicates from individual cycles were nearly $100 \%$ homogeneous (Fig. 2F). The return of cotton as a host in cycle 4 did not result in a genotype that was similar to the genotype when cotton was the previous host in cycle 2 . The field genotype was nearly undetectable after two cycles of Forrest followed by cotton. Differences were observed between CDCD (Fig. 2C) and DCDC (Fig. $2 \mathrm{E})$, suggesting that the rotation scheme does have different effects on genotype. In DCDC, predominant genotypes following cotton as a host in cycle 1 were similar, but only a small portion of the field genotype was still similar to genotypes following cycle 1 . Increases in nematode population density (Fig. 1) show that nematodes were reproducing and the predominant genotype after 120 
days was not similar to the original field genotype from genetic recombination. In contrast, CDCD genotypes from cycles 1 and 3 were similar to the field genotype, suggesting that nematodes able to remain viable in the soil were the only ones recovered.

\section{Discussion}

No previous study has looked at the effect of crop rotations on the predominant genotype in a population of reniform nematodes. Our results show that crop rotation influences the population structure of reniform nematode. There was an observed effect of rotation scheme on reniform nematode genotypes between the cropping schemes CDCD and DCDC, which both used the same hosts but in different sequences. Since the effect on genotype was influenced by host and rotation scheme, all rotation schemes were analyzed separately. Each cycle used the same original field genotype for comparison, but six independent analyses were performed to remove ambiguity of whether the effect was due to host or rotation cycle when comparing number of distinct population groupings.

Continuous cotton cropping appears to maintain diversity of population specific genotypes, but allows for genetic drift from the original field genotype. The most distinct effects were observed when resistant or susceptible soybean was used in the rotation scheme. Continuous soybean maintains the integrity of the original field genotype for a longer period of time and may be more useful
(A) BBBB

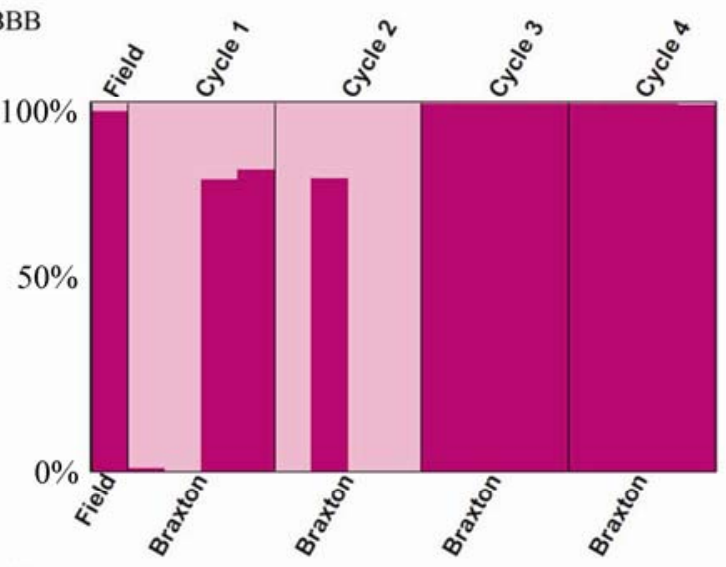

(C) $\mathrm{CDCD}$

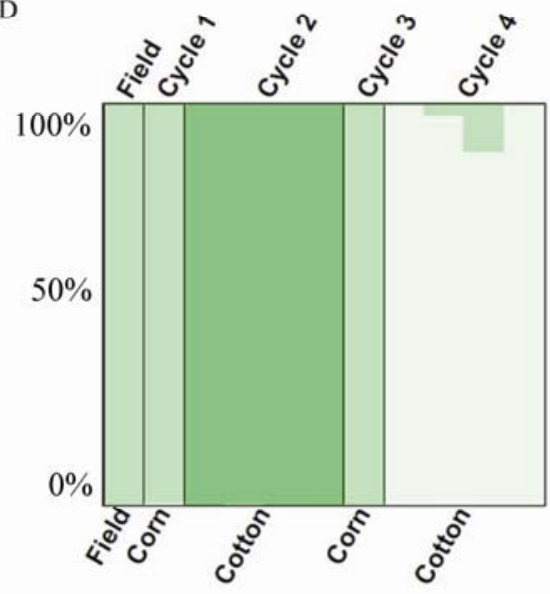

(E) DDDD

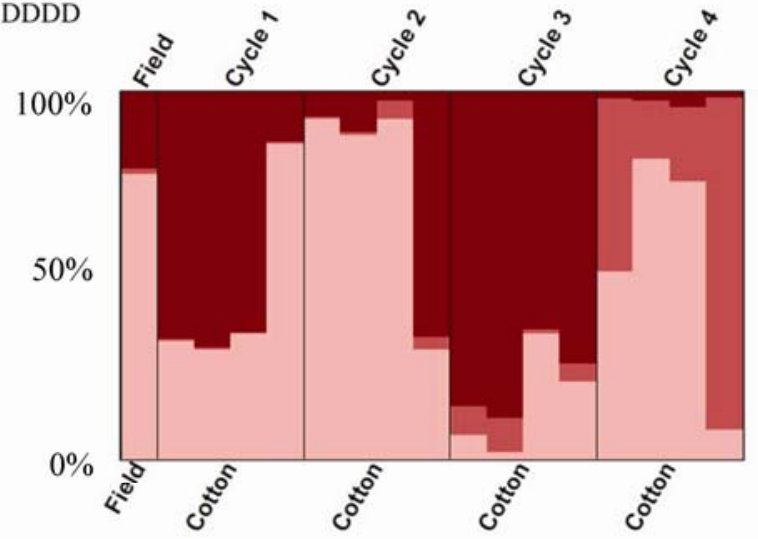

(B) $\mathrm{BCBC}$

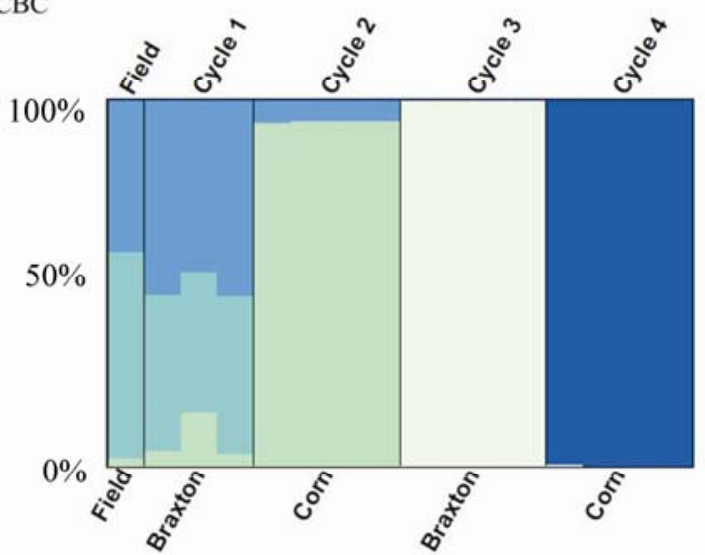

(D) DCDC

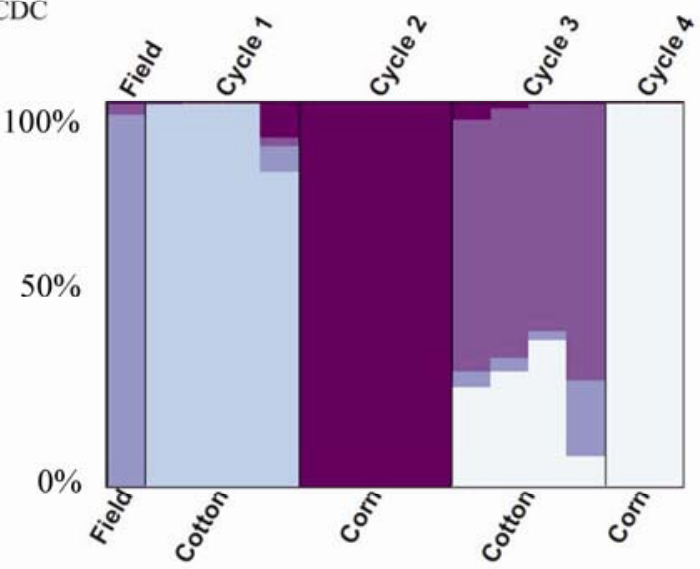

(F) FDFD

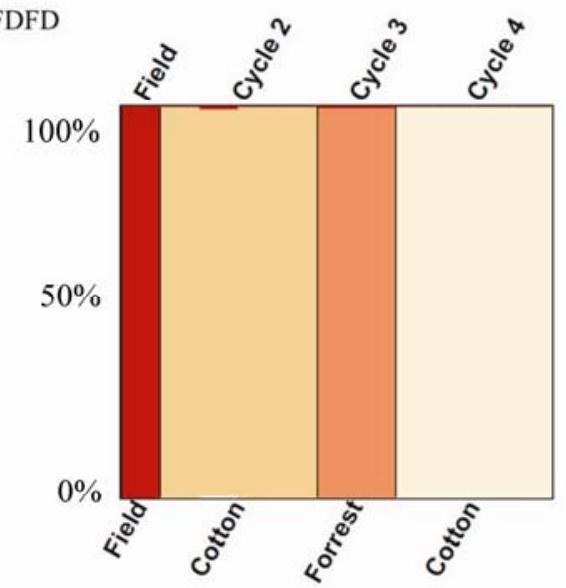

Fig. 2. Graphical representation of Rotylenchulus reniformis genotypes following four 120-day crop rotation cycles using six different rotation schemes. Images are produced from the program DISTRUCT and are based on population grouping assignments determined by the program STRUCTURE $\vee 2.3$. Each line on the X-axis represents the genotype of 1,000 reniform nematodes using four selective primer pairs with six (three in the forward and three in the reverse) selective nucleotides each. The Y-axis is percentage based, indicating the homogeneity between genotypes after each crop cycle. Each analysis was run independently, and a different color scheme was used for each rotation scheme in DISTRUCT. The field genotype is the same between all rotation schemes but is represented by a different color in each scheme due to population grouping differing based on each scheme. 
for maintaining field genotype when culturing reniform nematodes in a greenhouse. This may be a very relevant consideration in greenhouse maintenance of cultures used for resistance screening.

Similar results were found by Kaplan et al. (12) when studying host effect on Heterodera schachtii isolates. In their study, molecular markers (AFLPs and restriction fragment length polymorphisms) revealed several distinct genetic polymorphisms between three $H$. schachtii isolates subjected to two 80-day host sequences involving poor, moderate, and good hosts. Genetic polymorphisms for a population resulted from different host plants but also depended on the genotype of the initial population and host on which nematodes had been reared. Results showed rapid host-induced selection, which we also observed in our study with $R$. reniformis. Genotypic changes in nematode populations can be induced by plants of differing host suitability, which is similar to our results of genotype altering following crop rotations with resistant or poor hosts. Results for $H$. schachtii showed different geographic isolates responded differently to selection pressure exerted by particular hosts. Research aimed at identifying molecular markers able to discriminate population specific responses to crop rotations or use of host resistance can help to monitor or detect reniform nematode isolate variation. Understanding population response can help to extend the durability of resistance genes in host plants and avoid emergence of isolates able to reproduce on what has traditionally been considered a nonhost or poor host. Genetic differentiation in host associated forms of parasites has been reported for plant feeding insects. In the snakeweed grasshopper (Hesperotettix viridis), a genetically distinct lineage associated with two host plants, Solidago mollis and Gutierrezia sarothrae, has been accompanied by substantial genetic differentiation between the host associated forms. Genetic differentiation between the host associated forms is also maintained even when the two co-occur at the same site. Data suggest that lineages arose from a single ancestral host shift as opposed to local adaptation and subsequent genetic differentiation (26).

AFLP markers have been shown to be a suitable method for differentiating host-correlated intraspecific variants of fungi and nematodes. In Monilinia laxa, AFLP analysis showed isolates were correlated to host genus and not to geographic origin (9). These findings also genetically supported the specialization of isolates from apple trees forming the forma specialis taxonomic group mali, adapted to the specific host apple trees. Two forms of the causal agent of net blotch of barley, Pyrenophora teres f. teres and $P$. teres f. maculata, were distinguished using AFLP markers even though the two groups are morphologically similar but cause different symptoms (14). AFLP analysis distinguished between different host races of the tobacco cyst nematode complex (15). Markers were identified that distinguished two of the tobacco cystnematode subgroups, Globodera tabacum tabacum and Globodera tabacum solanacearum, even when the two had the same geographic origin. In Ditylenchus dipsaci, the stem and bulb nematode, 30 morphologically similar biological races have been described according to their host preferences $(11,25)$. The only race that could be distinguished morphologically due to body size was more harmful to Vicia faba (faba bean) and has been termed a "giant" type in contrast to "normal" types. AFLP analysis showed clear distinction between giant and normal populations of D. dipsaci, suggesting that each should be considered a distinct species (5).

Selection for host specific pathotypes able to break resistance may result from the use of a continuous rotation scheme and can lead to the need for a race schematic to characterize reniform nematode variants. AFLP markers may prove to be a useful molecular tool for characterizing variants and monitoring emergence of pathotypes. Population responses to host plants will assist in crop-mediated management options for aid in identifying stable resistance genes. Assessment of long-term host-induced selection in the field can help determine whether markers are useful in resistance management. This is the first report of host effect on population structure of $R$. reniformis following prescribed crop rotations.
Future research for $R$. reniformis would need to include various geographic isolates to determine the extent of variability within the species in the response to host selection pressure.

\section{Literature Cited}

1. Blasingame, D., Patel, M. V., Larence, K., Gazaway, W., Olsen, M., Kirkpatrick, T., Monfort, S., Davis, M., Marios, M., Kemerait, B., Colyer, P., Scuimbata, G., Lawrence, G., Wrather, A., Goldberg, N., Koenning, S., Pitts, J. T., Muller, J., Newman, M., Woodward, J., Wheeler, T., and Phipps, P. 2010. 2009 Cotton disease loss estimate committee report. Proc. Beltwide Cotton Conf. 1:237-240.

2. Brown, S. M., Culpepper, S., Harris, G., Kemerait, B., Roberts, P., Shurley, D., and Ziehl, A. 2008. 2008 Georgia cotton production guide. UGA Cotton Web Page. www.ugacotton.com.

3. Davis, R. F., Koenning, S. R., Kemerait, R. C., Cummings, T. D., and Shurley, W. D. 2003. Rotylenchulus reniformis management in cotton with crop rotation. J. Nematol. 35 (1):58-64.

4. Davis, R. F., and Webster, T. M. 2005. Relative host status of selected weeds and crops for Meloidogyne incognita and Rotylenchulus reniformis. J. Cotton Sci. 9:41-46.

5. Esquibet, M., Grenier, E., Plantard, O., Andaloussi, F. A., and Caubel, G. 2003. DNA polymorphism in the stem nematode Ditylenchus dipsaci development of diagnostic markers for normal and giant races. Genome 46:10771083.

6. Gaur, H. S., and Perry, R. N. 1991. The biology and control of the plant parasitic nematode Rotylenchulus reniformis. Agric. Zool. Rev. 4:177-212.

7. Gazaway, W. S., Akridge, J. R., and McLean, K. 2000. Impact of various crop rotations and various winter cover crops on reniform nematode in cotton. Proc. Beltwide Cotton Conf. 1:162-163.

8. Gazaway, W. S., Akridge, J. R., and Rodriguez-Kabana, R. 1998. Management of reniform nematode in cotton using various rotation schemes. Proc. Beltwide Cotton Conf., National Cotton Council, Memphis, TN:141-142.

9. Gril, T., Celar, F., Munda, A., Javornik, B., and Jakse, J. 2008. AFLP analysis of intraspecific variation between Monilinia laxa isolates from different hosts. Plant Dis. 92:1616-1624.

10. Hubisz, M. J., Falush, D., Stephens, M., and Pritchard, J. K. 2009. Inferring weak population structure with the assistance of sample group information. Mol. Ecol. Resour. 9:1322-1332.

11. Janssen, G .J. W. 1994. The relevance of races in Ditylenchus dipsaci (Kühn) Filipjev, the stem nematode. Fundam. Appl. Nematol. 17:469-473.

12. Kaplan, M., Caswell-Chen, E. P., and Williamson, V. M. 1999. Assessment of host-induced selection on three geographic isolates of Heterodera schachtii using RAPD and AFLP markers. Phytopathology 89:68-73.

13. Koenning, S. 2010. Disease management in cotton. 2010. Cotton Information prepared by the North Carolina Cooperative Extension Service College of Agriculture and Life Sciences NC State University:54-65.

14. Lehmensiek, A., Bester-van der Merwe, A. E., Sutherland, M. W., Platz, G., Kriel, W. M., Potgieter, G. F., and Prins, R. 2010. Population structure of South African and Australian Pyrenophora teres isolates. Plant Pathol. 59:504-515.

15. Marché, L., Valette, S., Grenier, E., and Mugniéry, D. 2001. Intra-specific DNA polymorphism in the tobacco cyst nematode complex (Globodera tabacum) characterized by AFLP. Genome 44:941-946.

16. Muller, J. 1992. Detection of pathotypes by assessing the virulence of Heterodera-schachtii populations. Nematologica 38:50-64.

17. Newman, M. A. 2010. Cotton production in Tennessee. UT cotton production guide:24-25.

18. Plunkett, D. E., Kirkpatrick, T. L., Harmon, B., Matlock, R., Robertson, W. C., and Ross, J. 2003. Using an integrated pest management rotational crop program to suppress reniform nematode. Proc. Beltwide Cotton Conf., National Cotton Council: A25-A28.

19. Plunkett, D. E., Kirkpatrick, T. L., Matlock, R., and Talley, R. W. 2002. Reniform reduction in CRVP fields through crop rotation. Proc. Beltwide Cotton Conf., National Cotton Council, Memphis, TN.

20. Robinson, A. F., Bell, A. A., Dighe, N. D., Menz, M. A., Nichols, P. L., and Stelly, D. M. 2007. Introgression of resistance to nematode Rotylenchulus reniformis into upland cotton (Gossypium hirsutum) from Gossypium longicalyx. Crop Sci. 47:1865-1877.

21. Robinson, A. F., Cook, C. G., and Percival, A. E. 1999. Resistance to Rotylenchulus reniformis and Meloidogyne incognita race 3 in the major cotton cultivars planted since 1950. Crop Sci. 39:850-858.

22. Robinson, A. F., Inserra, R. N., Caswell-Chen, E. P., Vovlas, N., and Troccoli, A. 1997. Rotylenchulus species: Identification, distribution, host ranges, and crop plant resistance. Nematropica 27:127-180.

23. Rosenberg, N. A. 2004. DISTRUCT: A program for the graphical display of population structure. Mol. Ecol. Notes 4:137-138.

24. Stetina, S. R., Young, L. D., Pettigrew, W. T., and Bruns, H. A. 2007. Effect of corn-cotton rotations on reniform nematode populations and crop yield. Nematropica 37:237-248.

25. Sturhan, D., and Brzeski, M. W. 1991. Stem and bulb nematodes, Ditylenchus spp. Pages 423-464 in: Manual of Agricultural Nematology. W. R. Nickle, ed. Marcel Dekker, New York.

26. Sword, G. A., Joern, A., and Senior, L. B. 2005. Host plant-associated ge- 
netic differentiation in the snakeweed grasshopper, Hesperotettix viridis (Orthoptera : Acrididae). Mol. Ecol. 14:2197-2205.

27. Turner, S. J., and Fleming, C. C. 2002. Multiple selection of potato cyst nematode Globodera pallida virulence on a range of potato species. I. Serial selection on Solanum-hybrids. Eur. J. Plant Pathol. 108:461-467.

28. Usery, S. R., Lawrence, K. S., Lawrence, G. W., and Burmester, C. H. 2005.
Evaluation of cotton cultivars for resistance and tolerance to Rotylenchulus reniformis. Nematropica 35:121-133.

29. Vos, P., Hogers, R., Bleeker, M., Reijans, M., Vandelee, T., Hornes, M., Frijters, A., Pot, J., Peleman, J., Kuiper, M., and Zabeau, M. 1995. AFLP A new technique for DNA-fingerprinting. Nucleic Acids Res. 23:44074414. 